\title{
Article \\ Mastering of NIL Stamps with Undercut T-Shaped Features from Single Layer to Multilayer Stamps
}

\author{
Philipp Taus ${ }^{1}$, Adrian Prinz ${ }^{2}$, Heinz D. Wanzenboeck ${ }^{1, *}$, Patrick Schuller ${ }^{1}$, Anton Tsenov ${ }^{1}$, Markus Schinnerl ${ }^{1}$, \\ Mostafa M. Shawrav ${ }^{3}$, Michael Haslinger ${ }^{4}$ (D) and Michael Muehlberger 4 (D) \\ 1 TU Wien, Institute for Solid State Electronics, 1040 Vienna, Austria; philipp.taus@tuwien.ac.at (P.T.); \\ patrick.schuller@tuwien.ac.at (P.S.); anton.tsenov@tuwien.ac.at (A.T.); markus.schinnerl@tuwien.ac.at (M.S.) \\ 2 Stratec Consumables GmbH, 5081 Anif, Austria; a.prinz@stratec.com \\ 3 ams AG, Tobelbader Strasse 30, 8141 Premstaetten, Austria; mostafa.shawrav@gmail.com \\ 4 PROFACTOR GmbH, 4407 Steyr, Austria; michael.haslinger@profactor.at (M.H.); \\ michael.muehlberger@profactor.at (M.M.) \\ * Correspondence: heinz.wanzenboeck@tuwien.ac.at; Tel.: +43-1-588-36243
}

\section{check for}

updates

Citation: Taus, P.; Prinz, A.; Wanzenboeck, H.D.; Schuller, P.; Tsenov, A.; Schinnerl, M.; Shawrav, M.M.; Haslinger, M.; Muehlberger, M. Mastering of NIL Stamps with Undercut T-Shaped Features from Single Layer to Multilayer Stamps. Nanomaterials 2021, 11, 956. https:// doi.org/10.3390/nano11040956

Academic Editor:

Konstantins Jefimovs

Received: 25 February 2021

Accepted: 19 March 2021

Published: 9 April 2021

Publisher's Note: MDPI stays neutral with regard to jurisdictional claims in published maps and institutional affiliations.

Copyright: (C) 2021 by the authors Licensee MDPI, Basel, Switzerland. This article is an open access article distributed under the terms and conditions of the Creative Commons Attribution (CC BY) license (https:// creativecommons.org/licenses/by/ $4.0 /)$.

\begin{abstract}
Biomimetic structures such as structural colors demand a fabrication technology of complex three-dimensional nanostructures on large areas. Nanoimprint lithography (NIL) is capable of large area replication of three-dimensional structures, but the master stamp fabrication is often a bottleneck. We have demonstrated different approaches allowing for the generation of sophisticated undercut T-shaped masters for NIL replication. With a layer-stack of phase transition material (PTM) on poly-Si, we have demonstrated the successful fabrication of a single layer undercut T-shaped structure. With a multilayer-stack of silicon oxide on silicon, we have shown the successful fabrication of a multilayer undercut T-shaped structures. For patterning optical lithography, electron beam lithography and nanoimprint lithography have been compared and have yielded structures from $10 \mu \mathrm{m}$ down to $300 \mathrm{~nm}$. The multilayer undercut T-shaped structures closely resemble the geometry of the surface of a Morpho butterfly, and may be used in future to replicate structural colors on artificial surfaces.
\end{abstract}

Keywords: nanoimprint lithography (NIL); undercut features; master; Blu-Ray patterning; reactive ion etching

\section{Introduction}

In biology, surfaces with three-dimensional nanostructures are responsible for outstanding physicochemical properties of the surface. The anti-wetting surface of the lotus flower, the low friction surface of shark skin and the high sticking capability of Gecko feet are well-described. Another exceptional example is structural color: Not chemical pigmentation, but a complex structured multilayered nanostructure, is the cause of the brilliant blue wing colors in some of the species of morpho butterflies and the golden color of the beetle Chrysina aurigans [1,2].

Imitating nature's nanostructured surfaces by engineering methods promises to gain the same spectacular properties on human-made products. The biomimetic replication of a lotus-like surface for anti-wetting features has been described [3]. A wide range of lithographic methods has been successfully applied for three-dimensionally structured surfaces [4-7]. However, many methods can only generate these biomimetic structures on a small area. The challenge is the fabrication on a larger surface area-here nanoimprint lithography has a lot of potential [8].

Nanoimprint lithography (NIL) is a cost-effective method to replicate nanostructures on large areas $[9,10]$. A nanostructured stamp is used to mechanically emboss a polymer layer on a substrate [11]. Such three-dimensionally structured surfaces are interesting for microfluidic channels [12,13], superhydrophobic surfaces [14], and optical applications [15,16]. 
Also undercut structures [11,17] and hierarchical structures [18] can be fabricated. With an imprint stepper or with roll-to-roll NIL also large areas can be patterned threedimensionally. For fabrication of three-dimensional structures hybrid structuring processes combining NIL and electron beam lithography $[19,20]$ or NIL and photolithography [21], as well as multilayer nanoimprinting [22] to create hierarchical stamp masters for optical micro- and nanostructures have been recently demonstrated successfully. Even imprinting of complex three-dimensional nanomolds [23] was successfully demonstrated.

In contrast to the layer by layer fabrication with conventional multilevel lithography, the NIL fabrication allows to directly replicate a complete 3D structure in a single patterning step [24]. Master stamps are a critical component in the nanoimprint process. While initially these masters were directly used as stamps, now it is more common to replicate a working stamp from the original master and then use this working stamp for the actual nanoimprint process of the final product.

Often the masters are made from silicon wafers using well-established silicon technology, like electron beam lithography or interference lithography combined with reactive ion etching [10], but also biological samples can be used to directly replicate bionic structures $[4,25]$. The fabrication of three-dimensional master stamps has also been achieved by focused ion beam related methods [26,27] or by grey scale lithography [28].

The replication of nanostructures in the nanoimprint process is commonly limited to draft angles equal or smaller than $90^{\circ}$, but recently it was also shown that undercut structures as well as nano-cavities could be replicated when the right materials for the stamp and imprint material are chosen [11,29]. The process parameters of the replicationespecially of the demolding step-are critical for freeform microstructures [30]. Also, innovative alternatives such as shape memory polymers have been reported [31,32]. Not only is the replication process a challenge, but also the fabrication of the master itself.

The objective of this work is to fabricate the multilevel nanostructured surface resembling geometry of a Morpho menelaus wing. The challenge is that multilayer undercut features have to be fabricated. Such structures are not only beneficial for biomimetic structures, a similar requirement also exists for vertical-channel solid-state memory [33,34]. This paper describes and compares the fabrication of (A) single-layer undercut T-structures using PTM-layers (phase transition material) on silicon as well as (B) multi-layer undercut T-structures of a Si-SiO ${ }_{2}$-multi-stack (Table 1). The PTM-layers on silicon were patterned mask-less by Blu-Ray laser writing [35]. The $\mathrm{Si}_{-} \mathrm{SiO}_{2}$-multi-stack was etched by RIE using gold hardmasks patterned by three different lithography methods-optical lithography, electron beam lithography, and NIL.

Table 1. Overview of five process sequences used to fabricate undercut T-structures

\begin{tabular}{|c|c|c|c|c|c|}
\hline T-Structure & \multirow{2}{*}{\multicolumn{2}{|c|}{$\begin{array}{l}\text { Single-Layer } \\
\text { Blu-Ray laser }\end{array}$}} & \multicolumn{3}{|c|}{ Multi-Layer } \\
\hline Patterning & & & g-line lithography & e-beam lithography & NIL \\
\hline Lift-off mask & & - & AZ5214E & PMMA & mr-NIL212 \\
\hline Etch-mask & Inorg & PTM-layer & & Au-hardmask & \\
\hline Etch Step 1 & \multirow{2}{*}{$\mathrm{KOH}$ wet etch } & \multirow{2}{*}{ Medium pressure RIE } & \multicolumn{3}{|c|}{ Low pressure RIE } \\
\hline Etch Step 2 & & & \multicolumn{3}{|c|}{ High pressure RIE } \\
\hline
\end{tabular}

\section{Materials and Methods}

As substrate for the master, $\mathrm{Si}(100)$ wafers were used. These wafers were used to fabricate two types of masters: (i) single-layer undercut structures with a T-shaped crosssection and (ii) multilayer undercut structures with a T-on-top-of-T-shaped cross-section. To accomplish these structures, a multilayer stack of different materials was deposited by sputter deposition. The materials deposited were silicon, silicon oxide and phase transition material (PTM) [36]. The lateral structure was defined by lithographic patterning of the top layer as described in the following sections: 


\subsection{Single Layer Undercut Masters}

To prepare the single-layer T-shaped masters (see Figure 1) a layer stack of PTM $\left(\mathrm{MoWO}_{\mathrm{x}}\right)$, amorphous silicon (a-Si) and PTM were deposited on a $200 \mathrm{~mm} \mathrm{Si}$ wafer by sputter deposition. The top PTM layer was $50 \mathrm{~nm}$ thick and was processed to act as a hard mask. The bottom PTM layer served as an etch-stop layer. For patterning of the top layer, the PTR-3000 phase transition mastering system (Sony Disc Technology Inc., Tokyo, Japan) was used. The PTR 3000 system was developed for Blu-Ray mastering and uses a $405 \mathrm{~nm}$ diode laser for exposure [37]. Blu-Ray mastering allows high-speed large area writing with resolutions down to $130 \mathrm{~nm}$ [35]. The phase transition material behaves comparable to a positive photoresist and changes from amorphous to polycrystalline upon laser irradiation. Compared to regular Blu-Ray mastering, this process used constant angular velocity writing with a rotation velocity of $450 \mathrm{rpm}$ and a $7.75 \mathrm{~ns}$ clock cycle, which results in pit sizes of $7.3 \mathrm{~nm}$ at $20 \mathrm{~mm}$ radius and $14.6 \mathrm{~nm}$ at $40 \mathrm{~mm}$. The pit-density was increased from inner tracks towards outer tracks (trackpitch $40 \mathrm{~nm}$ ) in software, to achieve a homogenous exposure. The exposed area can be developed using a 2.38\% TMAH wet chemistry for $2000 \mathrm{~s}$. With the top PTM layer as hard mask, the underlying layer of amorphous $\mathrm{Si}$ was wet etched using $25 \% \mathrm{KOH}$ solution at $40{ }^{\circ} \mathrm{C}$. As the amorphous $\mathrm{Si}$ lacks any crystalline order, the etching by $\mathrm{KOH}$ is isotropic and also etches sideways. The geometry of the undercut features was dependent on the duration of this isotropic etch process and was varied from $2-10 \mathrm{~min}$.

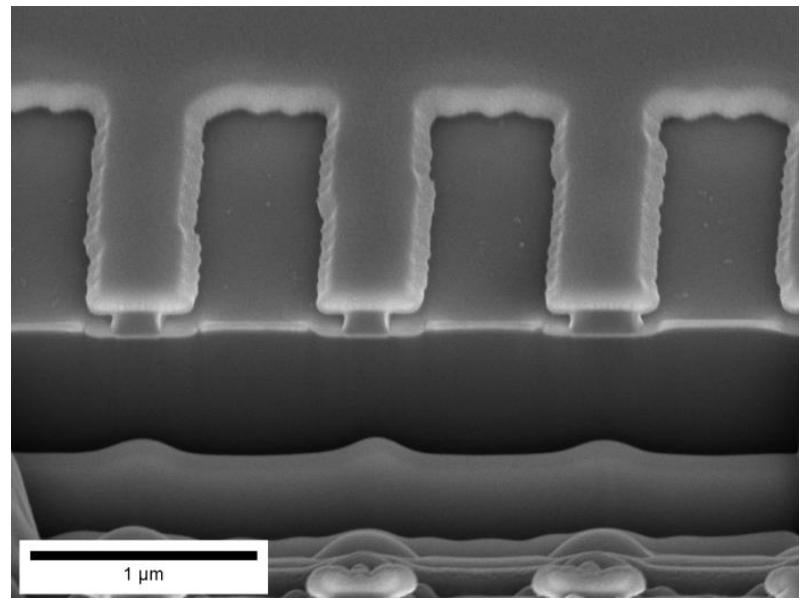

(a)

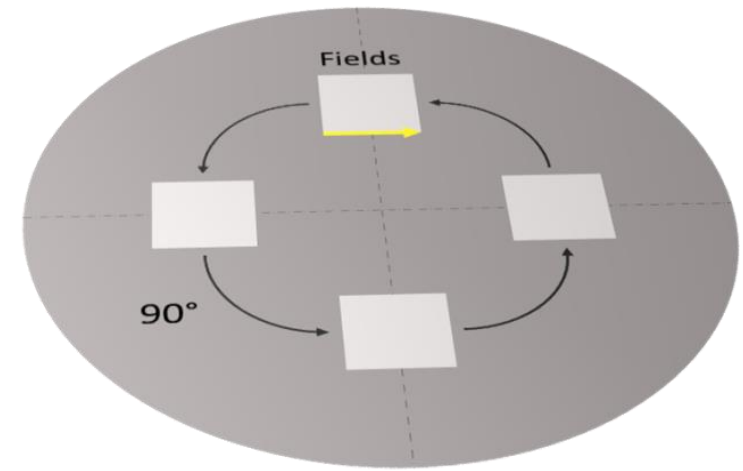

(c)

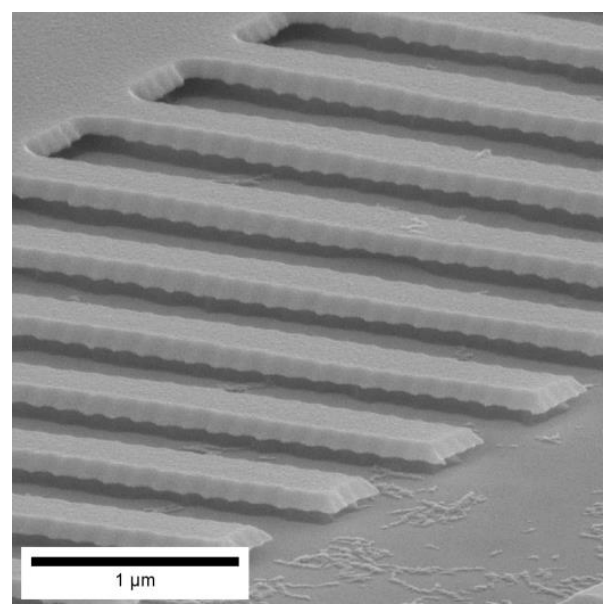

(b)

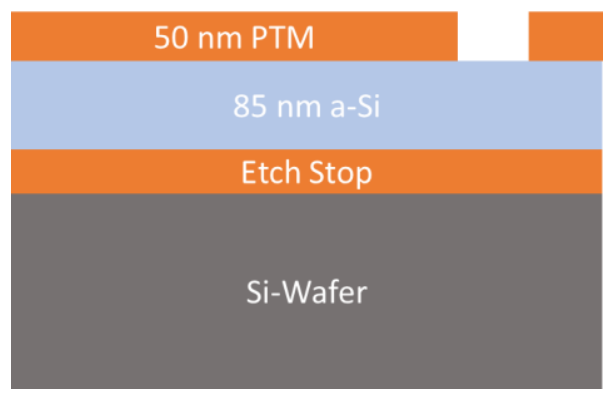

(d)

Figure 1. Single layer undercut master. (a) SEM image of a FIB-cross-section showing the underetched geometry (b) Tilted view SEM image of the single-layer underetched structures. The PTM top layer forms the overhanging ledge on top of the underetched Si base. (c) Optical image of wafer is indicating the Blu-Ray mastering of the top PTM layer (d) Schematic cross-section through the layer stack. 
Alternatively, also a reactive ion etching (RIE) process was developed to avoid wet chemical etching. An RF power setting of $30 \mathrm{~W}$ with a medium chamber pressure of 10 mTorr, a gas flow of $20 \mathrm{sccm} \mathrm{SF}_{6}$ and $10 \mathrm{sccm}$ Ar was used. The etch rate in Si was at least one magnitude faster than in the PTM-layer.

\subsection{Multilayer Undercut Masters}

This work was motivated by the wing surface of the Morpho butterfly, which is a periodic, multilayered ridge on the scales of the butterfly's wings [1,38]. To achieve multilayer undercut structures to resemble those found in the Morpho butterflies, the fabrication approach was adopted in three ways:

Firstly, as an etch mask, a lithographically patterned gold layer was used instead of the laser-patterned PTM layer. For lithography either (i) optical photolithography, (ii) electron beam lithography with $350 \mathrm{~nm}$ broad features, or (iii) nanoimprint lithography with $300 \mathrm{~nm}$ features were employed. For photolithography, AZ5214E (Microchemicals, Ulm, Germany) was used in image reversal mode to generate $1.6 \mu \mathrm{m}$ high resist patterns for the subsequent lift-off process. For electron beam lithography the PMMA-resist 950K A4 with a thickness of $220 \mathrm{~nm}$ was used, and the exposure of lines with a width of $350 \mathrm{~nm}$ was performed with a Raith e-line system at $10 \mathrm{kV}$ and a beam current of $200 \mathrm{pA}$. With electron beam lithography nanostructuring of larger areas requires inefficiently long exposure time. As an alternative for the nanopatterning of larger areas exceeding $1 \mathrm{~cm}^{2}$ NIL has proven to be a faster process [39]. For the NIL-made etch template a stamp with a checkerboard-style array of $300 \times 300 \mathrm{~nm}^{2}$ mesas was used to imprint these square structures into a NIL material layer. For fabrication of a metal nanomesh array a dual layer lift-off nanoimprint process using LOR1A (MicroChem Corp., Westborough, MA, USA) and mr-NIL212FC resist materials (micro resist technology $\mathrm{GmbH}$, Berlin, Germany) was used as described in [40].

A gold layer with $200 \mathrm{~nm}$ nominal thickness was deposited on the lithographic pattern by sputtering with $25 \mathrm{~W}$ power using a VonArdenne (Dresden, Germany) LS320 Sputter deposition system or by thermal evaporation using a Balzer's BAK600 (Oerlikon Balzers Coating AG, Brügg, Switzerland) thermal evaporation system. In both cases, a sub-10 nm Cr layer was deposited as an adhesion layer on the substrate. By lift-off, the metal hard mask for the further NIL master fabrication was obtained.

Secondly, instead of using a single $\mathrm{Si}$ layer, a stack of alternating $\mathrm{Si}_{-} \mathrm{SiO}_{2}$ layers was used, as sketched out in Figure $4 \mathrm{~b}$. The sputter deposited layer stack was comprised of 6 pairs of a $50 \mathrm{~nm}$ thick amorphous $\mathrm{Si}$ layer on top of an $85 \mathrm{~nm}$ thick $\mathrm{SiO}_{2}$ layer. For a multilayer structure, the individual Si-layers have to be separated by interspaces that can also be etched (to continue etching of the subsequently lower Si-layer). While the amorphous $\mathrm{Si}$ was the layer to be underetched sideways, the interspace layer should display a significantly lower etch rate sideways.

Therefore, thirdly, instead of the pure wet chemical etching a reactive ion etching (RIE) process was used. Dry etching was performed in an Oxford Instruments (Oxford Instruments Plasma Technology, Yatton, UK) Plasmalab 100 system using the process gases $\mathrm{SF}_{6}, \mathrm{O}_{2}$, and Ar. The process pressure was varied between 5 and $60 \mathrm{mTorr}$ to obtain optimal etching results. $\mathrm{Si}$ and $\mathrm{SiO}_{2}$ can both be dry etched by reactive ion etching (RIE) with a fluorine species, but the etch rate of $\mathrm{SiO}_{2}$ is significantly smaller. The PTM layer (as used in the previous section) is not a suitable mask layer for RIE, as it can only be wet etched after phase transition by blue light exposure.

The RIE process was optimized as a sequence of two etch steps: The first etch step was designed to etch anisotropically through the $\mathrm{Si} / \mathrm{SiO}_{2}$-stack. Hence, this first step was performed at $40 \mathrm{~W}$ RF power with a low chamber pressure ( $5 \mathrm{mTorr})$, for a higher bias voltage and longer mean free path length. Additionally, to quench the etch selectivity of $\mathrm{Si}$ over $\mathrm{SiO}_{2}$ during the anisotropic etch phase, also oxygen was added to the fluorine etchant (5 sccm SF $6,24 \mathrm{sccm} \mathrm{O} \mathrm{O}_{2}, 1 \mathrm{sccm} \mathrm{Ar}$ ). The oxidation of the surface of the Si-layer resulted in quenching the otherwise higher etch rate of $\mathrm{Si}$ in contrast to $\mathrm{SiO}_{2}$ and avoided a side etch 
into the Si during the anisotropic etch phase. Process step duration for anisotropic etching was in the range of $20 \mathrm{~min}$ to $60 \mathrm{~min}$ depending on the number of layers. In the second etch step ( $40 \mathrm{~W} \mathrm{RF})$, the underetching was performed by using a strongly isotropic etch process. In this second step, more fluorine and less oxygen was added $\left(20 \mathrm{sccm} \mathrm{SF}_{6}, 1 \mathrm{sccm}\right.$ $\mathrm{O}_{2}, 9 \mathrm{sccm} \mathrm{Ar}$ ), and the etch process with the F-species was performed at higher chamber pressure (30 mTorr). Tuned in such a way, this RIE process achieved the under-etching into the Si-layers within $30 \mathrm{~s}$. The resulting master stamp structures were inspected by scanning electron microscopy (SEM) (LEO 1530 VP, ZEISS Microscopy Jena, Germany). To recognize and to measure the undercut either SEM imaging with a tilted view angle or of a cross-section through the undercut structure was performed. Cross-sections were prepared by ion milling with a Zeiss Neon 40 EsB focused ion beam system (ZEISS Microscopy, Jena, Germany).

\section{Results}

The single-layer T-shaped masters demonstrate the feasibility to fabricate undercut structures also on a large scale. The PTM hard mask [41] was manufactured by Blu-Ray mastering, which is an industrial production technique used for optical memory devices of $120 \mathrm{~mm}$ diameter. For these Blu-Ray discs also industrial fabrication equipment exists and fabrication of large quantities has been proven. Using the same industrial fabrication environment for NIL masters opens a quickly accessible supply route for NIL masters at low costs. Figure 1 shows the successful realization of a NIL master with a single layer undercut structure.

As test structures, four squares of $25 \times 25 \mathrm{~mm}$ were patterned (see Figure 1c). The Blu-Ray-technology-based patterning yielded sub- $\mu \mathrm{m}$ structures that serve as an etch mask and subsequently as the suspended lamellae. Etching of the exposed PTM material revealed a line edge roughness in the range of $20 \mathrm{~nm}$. This is assumedly due to the spacing between the writing tracks, which leads to a curved front of phase transition. For exposure, the orthogonal pattern of our master had to be translated into exposure intervals on the spiral-shaped tracks that the laser was writing on the rotating substrate.

The patterned PTM layer was used as a hard mask to etch the aSi-layer in a wet isotropic $\mathrm{KOH}$ etch. As shown in the FIB-cross-section in Figure 1a the sideways underetch was in the range of $150 \mathrm{~nm}$. These single-layer undercut structures were successfully produced over an area of several $\mathrm{cm}^{2}$ (see Figure 2a). During etching of the Si-layer also the line edge roughness from the PTM layer is transferred into the Si-layer. The FIB-cross section of the underetched Si layer also shows that the distance of underetch is often not identical on the left and the right side (Figure 1a). With wet chemical etching, the diffusion in the underetched cavities is critical, and concentration gradient may lead to inhomogeneous etch rates on opposing sides of the same structure. Despite this restriction, the overall structure fidelity was good over large areas (Figure 1b). Preliminary experiments also demonstrated the feasibility to replicate the inverse structure by NIL. During demolding, the master remained widely intact, which indicates the excellent adhesion of the PTM-layer on the Si-layer (Figure 2a). Damage to the master structures was only evident on few positions throughout the substrate.

For the single layer undercut structure the PTM layer was both (a) laser-patterned hard mask on top and (b) etch stop layer below the Si-layer, which was to be underetched by $\mathrm{KOH}$. Alternatively, also a RIE-process was investigated to avoid the complications of wet chemical etching. Figure 3a shows the same structure as Figure 1 only that the underetching was performed by dry etching. It can be seen in Figure 3a that also the PTM etch stop layer for $\mathrm{KOH}$ has been etched, so that the etching continued into the Si substrate. For the T-structure, it is evident, that the top PTM-structure was diminished from an initial $50 \mathrm{~nm}$ thickness to a thickness below $20 \mathrm{~nm}$. The result was taken as stimulus to also use a quadruple stack of PTM-layer on top of a Si-layer. Etching such a multi-stack allowed to fabricate a dual layer undercut master and to demonstrate the feasibility to produce more 
complex undercut structures. However, the fluorine-based RIE process also etches the PTM hard mask on top (Figure 3b).

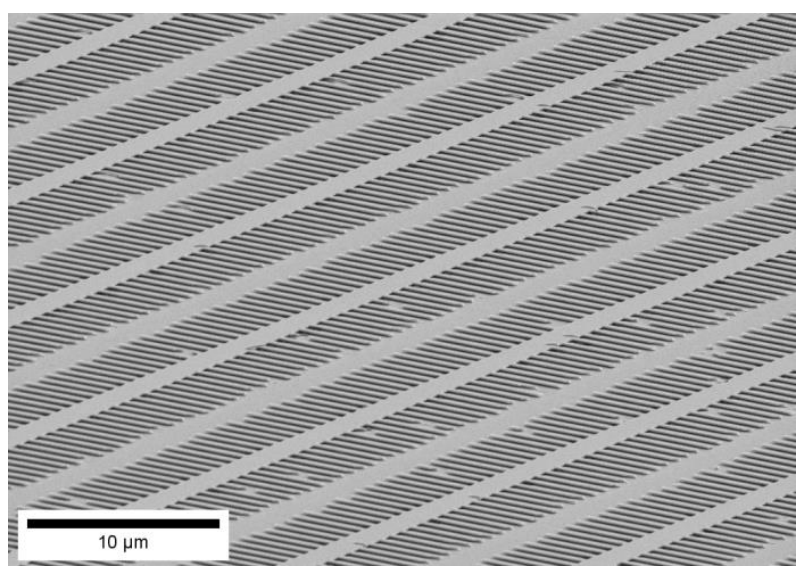

(a)

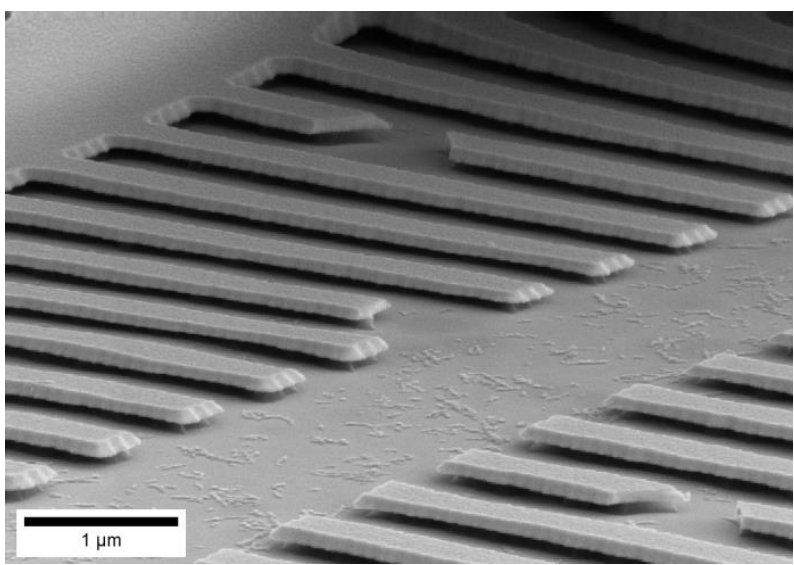

(b)

Figure 2. Defects on master after demolding from the NIL-substrate. (a) Overview image and (b) close-up of defect on master.

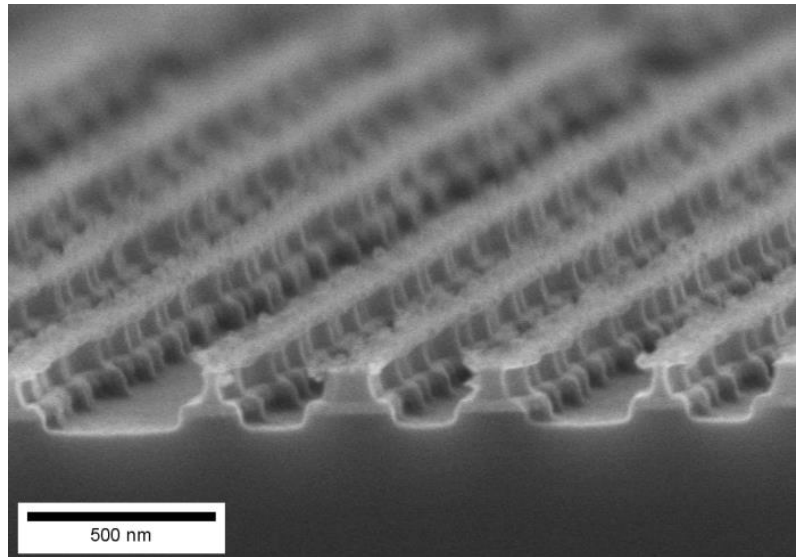

(a)

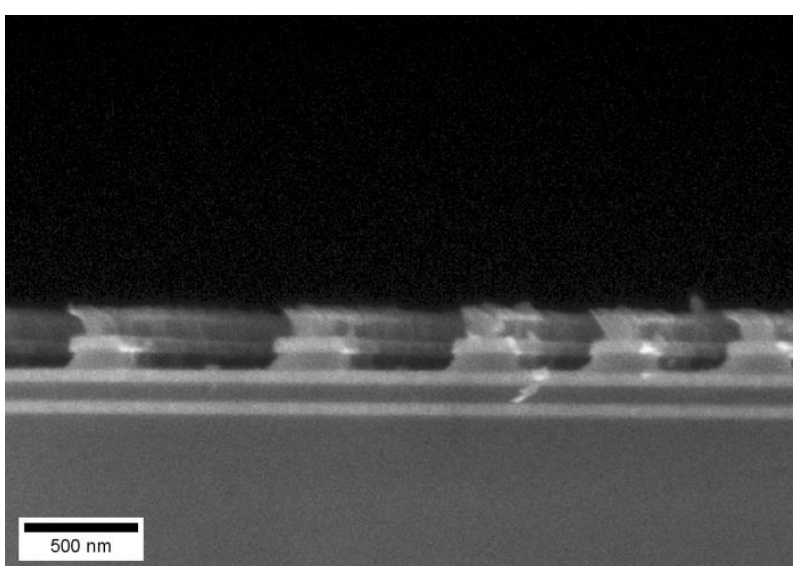

(b)

Figure 3. A PTM-Si-stack is etched by a F-based RIE process. (a) single layer PTM/Si-stack and (b) quadruple layer $\mathrm{PTM} / \mathrm{Si}$-stack. The cross-sections were fabricated by cleaving the wafer. Images were recorded by SEM on a vertically mounted master chip.

As PTM is both, the pattern defining hard mask and the interlayer between aSi-layers, the RIE process equally removes the PTM interlayer and the pattern-defining hard mask. We conclude that with the given material stack and the single-step RIE process no complex multilevel underetched structures are feasible.

For this reason, we progressed to a different material system- $-\mathrm{aSi}$ and $\mathrm{SiO}_{2}$ - for the multilayer undercut masters. Due to a size incompatibility of the PTM sputter systems with the $\mathrm{SiO}_{2}$ sputter system, patterning by Blu-Ray mastering had to be replaced by conventional lithography. As hard mask material, a gold layer was used. The hard mask for the sample shown in Figure $4 \mathrm{a}$ was a gold layer prepared by optical lithography and lift off. The multi-stack of $\mathrm{Si}$ and $\mathrm{SiO}_{2}$ is schematically illustrated in Figure $4 \mathrm{~b}$. The etching process was optimized by tuning the pressure and the mixture ratio of the etch gases $\mathrm{SF}_{6}$, $\mathrm{O}_{2}$, and Ar. By changing the gas composition, the pressure and the inductive power, a change from anisotropic to isotropic etching could be achieved. In the first RIE etch step the layer stack was anisotropically etched, while in a second etching step the Si-layers were isotropically etched sideways, while the $\mathrm{SiO}_{2}$ interspace layers were not etched significantly. This resulted in the multilevel underetched structure shown in Figure 4 . The hard mask 
for the sample shown in Figure 4a was a gold layer prepared by optical lithography and lift-off. Even after etching the gold layer is still present. This gives rise to the expectation, that even thicker layers or more layers could be processed by the same process. The high anisotropy of the first RIE step can be recognized by the vertical escape line of the corners of the $\mathrm{SiO}_{2}$ layers in Figure $4 \mathrm{a}$. The underetch into the Si-layer was in the range of $300 \mathrm{~nm}$ in top Si-layers down to $150 \mathrm{~nm}$ in bottom Si-layers. This gradually decreasing underetch width is analogous to the wing structure on Morpho butterfly. The wing structures are not in the $\mu \mathrm{m}$ range but the sub- $\mu \mathrm{m}$ range. Hence, smaller patterns with feature sizes in the $500 \mathrm{~nm}$ to $100 \mathrm{~nm}$ range were fabricated.

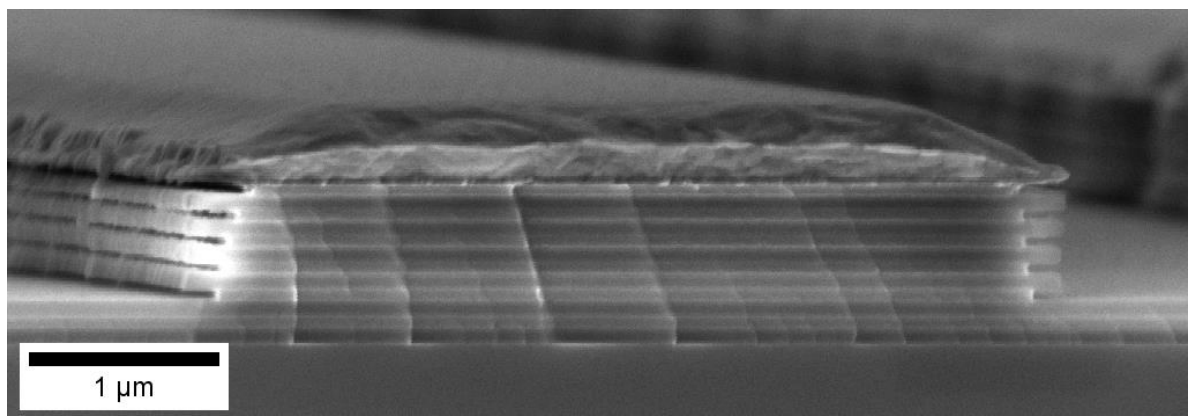

(a)

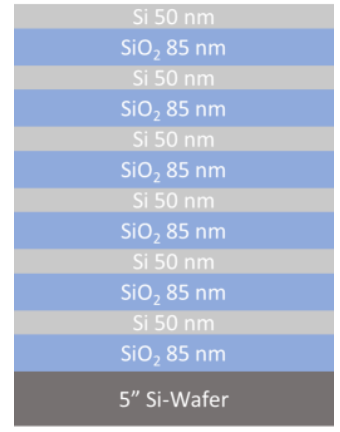

(b)

Figure 4. (a) A multilevel underetched structure with a gold mask defined by optical lithography. The lithographic structure is $5 \mu \mathrm{m}$ wide. SEM image on the cross-section of the layer stack after the dual-stage etching (first etch step stopped after Si layer \#5). (b) Schematic sequence of layers (without the gold hard mask).

To achieve these sub- $\mu$ m structures we used either electron beam lithography or nanoimprint lithography to prepare the hard mask pattern. An example obtained using e-beam lithography is shown in Figure 5. The sideways underetch distance of Si was in the range of 120 to $200 \mathrm{~nm}$. The remaining ridge of Si was already thin and reached the limit of mechanical stability. By shortening the duration of the second RIE etch step, also less undercut can be achieved. For a densely packed pattern of lines and spaces (Figure 5a) the anisotropic etch process did not yield a perfectly vertical envelope of the $\mathrm{SiO}_{2}$ lamellae. Increasing the spacing between lines (Figure $5 \mathrm{~b}$ ) yielded vertically aligned corners of the $\mathrm{SiO}_{2}$ lamellae. Also, here the amount of the sideways underetch into the Si layers decreased from top (more underetch) to bottom (less underetch). While the fabrication of multilevel undercut structures was demonstrated to be feasible also in the nm-range- a range that is relevant for biomimetic structures-the method of electron beam lithography is not suitable for patterning on large areas.

In a final experiment, we developed a process for larger area patterning of multilevel undercut structures. The industrial NIL replication using NIL-steppers and NIL roll-to-roll systems is excellently suited to fabricate 3D-structures on large areas. In this approach, twodimensional nanoimprint lithography was used to prepare the master for three-dimensional nanoimprint lithography. A NIL stamp with $300 \mathrm{~nm}$ features was used to fabricate a gold hard mask analogous to the previous experiments (see Figures 4 and 5). By a two-step RIE procedure this two-dimensional checkerboard pattern of the gold hardmask was transferred into a three-dimensional structure of the multilevel undercut master. Concluding, a threedimensional NIL master was fabricated using a two-dimensional NIL-patterned hard mask by etching and is shown in Figure 6.

The FIB-milled cross-section reveals four layers of undercut structures. Even with these $300 \mathrm{~nm}$ structures, a clear undercut could be achieved. For the top Si layer, the width of the remaining $\mathrm{Si}$ is below $50 \mathrm{~nm}$, which is already at the limit of the mechanical stability of the master. Similar to the Morpho butterfly wing structure, the structures get wider from top to bottom. With $300 \mathrm{~nm}$ features the resolution required for biomimicry of the blue butterfly wing of Morpho menelaus could be achieved. The repeated replication 
of NIL masters with multilayer undercut T-structures has already been demonstrated in [42] and marks an important step towards the reproducible fabrication of biomimetic nanostructures. With the availability of a production procedure for multilevel undercut master structures, the first step towards the technological use of NIL for structural colors has been made.

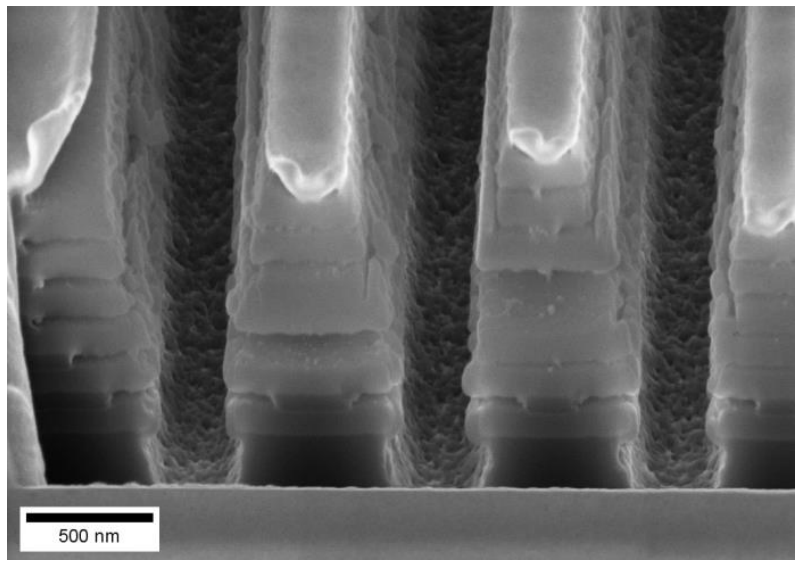

(a)

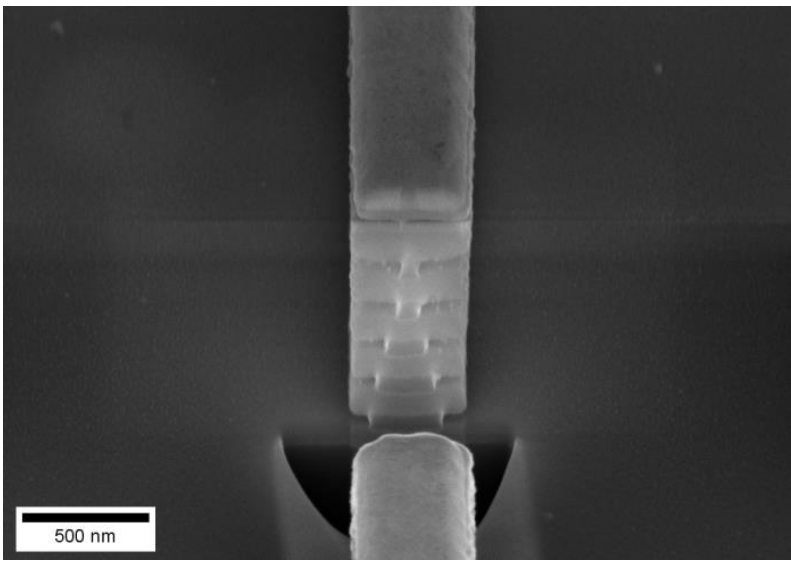

(b)

Figure 5. A multilevel underetched structure with a gold hard mask defined by electron beam lithography. (a) SEM image on the cross-section of the layer stack after etching. (a) Densely packed lines with little spacing. Lithographic structures are $400 \mathrm{~nm}$ (middle-left) and $350 \mathrm{~nm}$ (middle-right) wide. (b) Line with more than $1 \mu \mathrm{m}$ inter-line-distance. The lithographic structure is $350 \mathrm{~nm}$ wide.

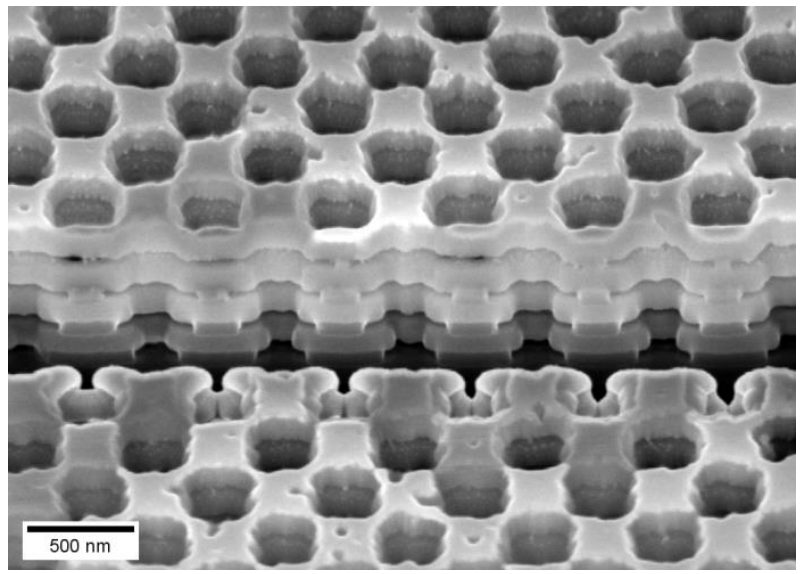

(a)

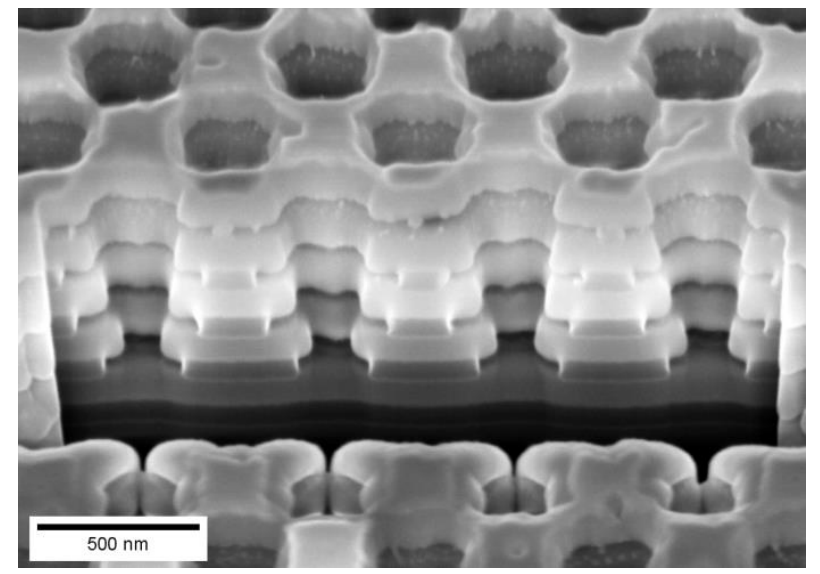

(b)

Figure 6. A multilevel underetched structure with a gold hard mask was defined by a NIL imprinted stamp. A 2D checkerboard structure consisting of $300 \times 300 \mathrm{~nm}^{2}$ squares was transferred into a metal layer acting as etch hardmask. The checkerboard pattern was transferred into the material by RIE etching. (a) Overview; (b) close-up.

\section{Conclusions}

Nanoimprint lithography is an exceptional patterning technique, as it can directly replicate three-dimensional structures. The availability of a three-dimensional master is a bottleneck of the NIL replication. In this work, we have presented fabrication technologies for undercut three-dimensional masters. With the structural design of our masters, we were inspired by the structural color of Morpho butterfly wings.

We have successfully demonstrated different ways to fabricate undercut nanoscale features on large areas. In a first step, a two-dimensional hard mask was prepared on a multilayer stack. In a subsequent two-stage RIE-process the undercut features were fabricated. The use of PTM hard masks allows using the industrially established method 
of laser writing as used for Blu-Ray mastering. Alternatively, also optical lithography, electron beam lithography and even nanoimprint lithography itself have been successfully demonstrated as alternative approaches to fabricate hard mask layers. With the industrially preferred RIE process, the problem-prone wet etching can be avoided. With the two-stage RIE process an industrially viable route to produce multilevel undercut structures was demonstrated. With an optimized process we could successfully show the fabrication of a four-layer undercut structure with $300 \times 300 \mathrm{~nm}$ features.

In future generations these approaches-PTM hard mask fabrication by Blu-Ray mastering and multilayer undercut etching by dual-stage RIE-may be combined. This will yield an industrially relevant fabrication approach for complex three-dimensional masters. The multilevel undercut master structures produced in this work are an essential component to further develop an imprinting and demolding procedure for complex undercut structures. NIL steppers and NIL roll-to-roll systems may transfer this approach to the industrial fabrication of structural colors on large areas.

Author Contributions: Conceptualization, P.T., A.P., H.D.W. and M.M.; Investigation, P.T., A.P., H.D.W., P.S., M.S., A.T., M.M.S. and M.H.; Writing-original draft preparation, H.D.W.; Writingreview and editing, H.D.W. and P.T.; Supervision, H.D.W.; Project administration, M.M. and H.D.W.; Funding acquisition, M.M. and H.D.W. All authors have read and agreed to the published version of the manuscript.

Funding: This research was funded by the Austrian Research Promotion Agency (FFG) under FFG-grant 843639 (project: "rollerNIL"). Open Access Funding by TU Wien.

Data Availability Statement: The data presented in this study are available on request from the corresponding author after agreeing to non-disclosure. The raw data are not publicly available due to non-disclosure agreements within the grant consortium.

Conflicts of Interest: The authors declare no conflict of interest.

\section{References}

1. Vukusic, P.; Sambles, J.R.; Lawrence, C.R.; Wootton, R.J. Quantified Interference and Diffraction in Single Morpho Butterfly Scales. Proc. R. Soc. B Biol. Sci. 1999, 266, 1403-1411. [CrossRef]

2. Vukusic, P.; Sambles, J.R. Photonic Structures in Biology. Nature 2003, 424, 852-855. [CrossRef] [PubMed]

3. Fernandez, A.; Francone, A.; Thamdrup, L.H.; Johanson, A.; Bilenberg, B.; Nielsen, T.; Guttmann, M.; Torres, C.M.S.; Kehagias, N. Design of Hierarchical Surfaces for Tuning Wetting Characteristics. Acs Appl. Mater. Interfaces 2017, 9, 7701-7709. [CrossRef] [PubMed]

4. Kirchner, R.; Guzenko, V.A.; Rohn, M.; Sonntag, E.; Mühlberger, M.; Bergmair, I.; Schift, H. Bio-Inspired 3D Funnel Structures Made by Grayscale Electron-Beam Patterning and Selective Topography Equilibration. Microelectron. Eng. 2015, 141, 107-111. [CrossRef]

5. Liddle, J.A.; Gallatin, G.M. Nanomanufacturing: A Perspective. ACS Nano 2016, 10, 2995-3014. [CrossRef]

6. Jiang, T.; Guo, Z.G.; Liu, W.M. Biomimetic Superoleophobic Surfaces: Focusing on Their Fabrication and Applications. J. Mater. Chem. A 2015, 3, 1811-1827. [CrossRef]

7. Luong-Van, E.; Rodriguez, I.; Low, H.Y.; Elmouelhi, N.; Lowenhaupt, B.; Natarajan, S.; Lim, C.T.; Prajapati, R.; Vyakarnam, M.; Cooper, K. Review: Micro-and Nanostructured Surface Engineering for Biomedical Applications. J. Mater. Res. 2013, 28, 165-174. [CrossRef]

8. Khan, S.; Lorenzelli, L.; Dahiya, R.S. Technologies for Printing Sensors and Electronics over Large Flexible Substrates: A Review. IEEE Sens. J. 2015, 15, 3164-3185. [CrossRef]

9. Busa, C.; Rickard, J.J.S.; Chun, E.; Chong, Y.; Navaratnam, V.; Oppenheimer, P.G. Tunable Superapolar Lotus-to-Rose Hierarchical Nanosurfaces via Vertical Carbon Nanotubes Driven Electrohydrodynamic Lithography. Nanoscale 2017, 9, 1625-1636. [CrossRef] [PubMed]

10. Schift, H. Nanoimprint Lithography: An Old Story in Modern Times? A Review. J. Vac. Sci. Technol. B Microelectron. Nanometer Struct. 2008, 26, 458-480. [CrossRef]

11. Möllenbeck, S.; Bogdanski, N.; Wissen, M.; Scheer, H.C.; Zajadacz, J.; Zimmer, K. Investigation of the Separation of 3D-Structures with Undercuts. Microelectron. Eng. 2007, 84, 1007-1010. [CrossRef]

12. Goh, W.H.; Hashimoto, M. Fabrication of 3D Microfluidic Channels and In-Channel Features Using 3D Printed, Water-Soluble Sacrificial Mold. Macromol. Mater. Eng. 2018, 303. [CrossRef]

13. Matsumoto, H.; Okabe, T.; Taniguchi, J. Microchannel Fabrication via Ultraviolet-Nanoimprint Lithography and Electron-Beam Lithography Using an Ultraviolet-Curable Positive-Tone Electron-Beam Resist. Microelectron. Eng. 2020, 226, 111278. [CrossRef] 
14. An, J.H.; Choi, J.S.; Kang, S.M. Reliable replication molding process for robust mushroom-shaped microstructures. J. Korean Soc. Precis. Eng. 2020, 37, 855-860. [CrossRef]

15. Finn, A.; Hensel, R.; Hagemann, F.; Kirchner, R.; Jahn, A.; Fischer, W.-J. Geometrical Properties of Multilayer Nano-ImprintLithography Molds for Optical Applications. Microelectron. Eng. 2012, 98, 284-287. [CrossRef]

16. Kirchner, R.; Chidambaram, N.; Schift, H. Benchmarking Surface Selective Vacuum Ultraviolet and Thermal Postprocessing of Thermoplastics for Ultrasmooth 3-D-Printed Micro-Optics. Opt. Eng. 2018, 57. [CrossRef]

17. Zimmer, K.; Zajadacz, J.; Fechner, R.; Dhima, K.; Scheer, H.-C. Fabrication of Optimized 3D Microstructures with Undercuts in Fused Silica for Replication. Microelectron. Eng. 2012, 98, 163-166. [CrossRef]

18. Mayer, A.; Rond, J.; Staabs, J.; Leifels, M.; Zajadacz, J.; Ehrhardt, M.; Lorenz, P.; Sunagawa, H.; Hirai, Y.; Zimmer, K.; et al. Multiple Replication of Hierarchical Structures from Polymer Masters with Anisotropy. J. Vac. Sci. Technol. B Nanotechnol. Microelectron. 2019, 37. [CrossRef]

19. Steinberg, C.; Rumler, M.; Runkel, M.; Papenheim, M.; Wang, S.; Mayer, A.; Becker, M.; Rommel, M.; Scheer, H.-C. Complex 3D Structures via Double Imprint of Hybrid Structures and Sacrificial Mould Techniques. Microelectron. Eng. 2017, 176, 22-27. [CrossRef]

20. Okabe, T.; Maebashi, H.; Taniguchi, J. Ultra-Violet Nanoimprint Lithography-Compatible Positive-Tone Electron Beam Resist for 3D Hybrid Nanostructures. Microelectron. Eng. 2019, 213, 6-12. [CrossRef]

21. Alameda, M.T.; Osorio, M.R.; Hernández, J.J.; Rodríguez, I. Multilevel Hierarchical Topographies by Combined Photolithography and Nanoimprinting Processes to Create Surfaces with Controlled Wetting. Acs Appl. Nano Mater. 2019, 2, 4727-4733. [CrossRef]

22. Moharana, A.R.; Außerhuber, H.M.; Mitteramskogler, T.; Haslinger, M.J.; Mühlberger, M.M. Multilayer Nanoimprinting to Create Hierarchical Stamp Masters for Nanoimprinting of Optical Micro-and Nanostructures. Coatings 2020, 10, 301. [CrossRef]

23. Deng, J.; Zhou, H.; Dong, J.; Cohen, P. Three-Dimensional Nanomolds Fabrication for Nanoimprint Lithography. In Procedia Manufacturing; Fratini, L., Wang, L., Ragai, I., Eds.; Elsevier, B.V.: Amsterdam, The Netherlands, 2019; Volume 34, pp. $228-232$.

24. Ofir, Y.; Moran, I.W.; Subramani, C.; Carter, K.R.; Rotello, V.M. Nanoimprint Lithography for Functional Three-Dimensional Patterns. Adv. Mater. 2010, 22, 3608-3614. [CrossRef] [PubMed]

25. Mühlberger, M.; Rohn, M.; Danzberger, J.; Sonntag, E.; Rank, A.; Schumm, L.; Kirchner, R.; Forsich, C.; Gorb, S.; Einwögerer, B.; et al. UV-NIL Fabricated Bio-Inspired Inlays for Injection Molding to Influence the Friction Behavior of Ceramic Surfaces. Microelectron. Eng. 2015, 141, 140-144. [CrossRef]

26. Waid, S.; Wanzenboeck, H.D.; Muehlberger, M.; Bertagnolli, E. Optimization of 3D Patterning by Ga Implantation and Reactive Ion Etching (RIE) for Nanoimprint Lithography (NIL) Stamp Fabrication. Microelectron. Eng. 2012, 97, 105-108. [CrossRef]

27. Waid, S.; Wanzenboeck, H.D.; Muehlberger, M.; Gavagnin, M.; Bertagnolli, E. Generation of 3D Nanopatterns with Smooth Surfaces. Nanotechnology 2014, 25. [CrossRef]

28. Schleunitz, A.; Schift, H. Fabrication of 3D Nanoimprint Stamps with Continuous Reliefs Using Dose-Modulated Electron Beam Lithography and Thermal Reflow. J. Micromech. Microeng. 2010, 20. [CrossRef]

29. Schrittwieser, S.; Haslinger, M.J.; Mitteramskogler, T.; Mühlberger, M.; Shoshi, A.; Brückl, H.; Bauch, M.; Dimopoulos, T.; Schmid, B.; Schotter, J. Multifunctional Nanostructures and Nanopocket Particles Fabricated by Nanoimprint Lithography. Nanomaterials 2019, 9, 1790. [CrossRef]

30. Burgsteiner, M.; Müller, F.; Lucyshyn, T.; Kukla, C.; Holzer, C. Influence of the Process Parameters on the Replication of Microstructured Freeform Surfaces. In Proceedings of the AIP Conference Proceedings, Rhodes, Greece, 22-28 September 2014; American Institute of Physics Inc.: College Park, MD, USA, 2014; Volume 1593, pp. 183-188.

31. Schneider, N.; Zeiger, C.; Kolew, A.; Schneider, M.; Leuthold, J.; Hölscher, H.; Worgull, M. Nanothermoforming of Hierarchical Optical Components Utilizing Shape Memory Polymers as Active Molds. Opt. Mater. Express 2014, 4, 1895-1902. [CrossRef]

32. Meier, T.; Bur, J.; Reinhard, M.; Schneider, M.; Kolew, A.; Worgull, M.; Hölscher, H. Programmable and Self-Demolding Microstructured Molds Fabricated from Shape-Memory Polymers. J. Micromech. Microeng. 2015, 25. [CrossRef]

33. Yun, J.-G.; Lee, J.D.; Park, B.-G. 3D NAND Flash Memory with Laterally-Recessed Channel (LRC) and Connection Gate Architecture. Solid-State Electron. 2011, 55, 37-43. [CrossRef]

34. Kim, Y.; Cho, S.; Lee, G.S.; Park, I.H.; Lee, J.D.; Shin, H.; Park, B.G. 3-Dimensional Terraced NAND (3D TNAND) Flash Memory-Stacked Version of Folded NAND Array. Ieice Trans. Electron. 2009, E92-C, 653-658. [CrossRef]

35. Kouchiyama, A.; Aratani, K.; Takemoto, Y.; Nakao, T.; Kai, S.; Osato, K.; Nakagawa, K. High Resolution Blue Laser Mastering with Inorganic Photoresist. In Proceedings of the International Symposium on Optical Memory and Optical Data Storage Topical Meeting, Waikoloa, HI, USA, 7-11 July 2002; pp. 27-29.

36. Raoux, S.; Rettner, C.T.; Jordan-Sweet, J.L.; Kellock, A.J.; Topuria, T.; Rice, P.M.; Miller, D.C. Direct Observation of Amorphous to Crystalline Phase Transitions in Nanoparticle Arrays of Phase Change Materials. J. Appl. Phys. 2007, 102. [CrossRef]

37. Meinders, E.R.; Rastogi, R.; Van Der Veer, M.; Peeters, P.; El Majdoubi, H.; Bulle, H.; Millet, A.; Bruls, D. Phase-Transition Mastering of High-Density Optical Media. Jpn. J. Appl. Phys. Part 1 Regul. Pap. Short Notes Rev. Pap. 2007, 46, $3987-3992$. [CrossRef]

38. Giraldo, M.A.; Yoshioka, S.; Liu, C.; Stavenga, D.G. Coloration Mechanisms and Phylogeny of Morpho Butterflies. J. Exp. Biol. 2016, 219, 3936-3944. [CrossRef] 
39. Bergmair, I.; Dastmalchi, B.; Bergmair, M.; Saeed, A.; Hilber, W.; Hesser, G.; Helgert, C.; Pshenay-Severin, E.; Pertsch, T.; Kley, E.B.; et al. Single and Multilayer Metamaterials Fabricated by Nanoimprint Lithography. Nanotechnology 2011, 22. [CrossRef] [PubMed]

40. Haslinger, M.J.; Mitteramskogler, T.; Kopp, S.; Leichtfried, H.; Messerschmidt, M.; Thesen, M.W.; Mühlberger, M. Development of a Soft UV-NIL Step\&repeat and Lift-off Process Chain for High Speed Metal Nanomesh Fabrication. Nanotechnology $2020,31$. [CrossRef]

41. Wuttig, M.; Yamada, N. Phase-Change Materials for Rewriteable Data Storage. Nat. Mater. 2007, 6, 824-832. [CrossRef] [PubMed]

42. Mühlberger, M.; Stephan, S.R.; Nees, D.; Moharana, A.; Belegratis, M.R.; Taus, P.; Kopp, S.; Wanzenboeck, H.D.; Prinz, A.; Fechtig, D. Nanoimprint Replication of Biomimetic, Multilevel Undercut Nanostructures. Nanomaterials 2021. accepted. 